\title{
DỨBin
}

Technological University Dublin

ARROW@TU Dublin

\section{DAB Eureka-147: The European Vision for Digital Radio}

\author{
Brian O'Neill \\ Technological University Dublin, brian.oneill@tudublin.ie
}

Follow this and additional works at: https://arrow.tudublin.ie/aaschmedcon

Part of the Broadcast and Video Studies Commons, Communication Technology and New Media Commons, and the Film and Media Studies Commons

\section{Recommended Citation}

O'Neill, B. 'DAB Eureka-147: The European Vision for Digital Radio'. Pre-Conference: The Long History of New Media: Contemporary and Future Developments Contextualized, International Communication Association, Annual Convention. Montréal, May 20 - 25, 2008.

This Conference Paper is brought to you for free and open access by the School of Media at ARROW@TU Dublin. It has been accepted for inclusion in Conference Papers by an authorized administrator of ARROW@TU Dublin. For more information, please contact arrow.admin@tudublin.ie, aisling.coyne@tudublin.ie, gerard.connolly@tudublin.ie.

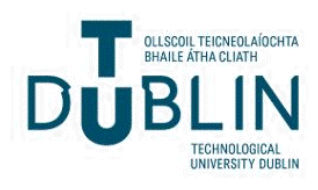




\title{
International Communication Association
}

\section{Communication History Interest Group Pre-conference Workshop}

The Long History of New Media: Contemporary and Future Developments Contextualized

\author{
Montreal, 22 May 2008
}

\section{DAB Eureka-147: The European Vision for Digital Radio}

\author{
Brian O’Neill, PhD \\ Faculty of Applied Arts \\ Dublin Institute of Technology \\ Rathmines Road, Dublin 6, IRELAND \\ Email: brian.oneill@dit.ie \\ Tel: +353-1-4023481
}

Author Bio: Brian O'Neill is based in the Faculty of Applied Arts, Dublin Institute of Technology. His research and teaching interests are in media literacy and policy on aspects of technology, new media, and information society issues. He is a member of the Digital Radio Cultures in Europe research group (COST Action A20) and Deputy Head of the IAMCR Audience and Reception Studies section. 


\section{DAB Eureka-147: The European Vision for Digital Radio}




\section{Abstract}

The digitalisation of radio broadcasting has a long history and as a project has been under active consideration for at least 25 years. A number of different technical approaches to digital radio exist, the longest established of which is the so-called Eureka-147 or DAB (Digital Audio Broadcasting) system. This paper explores the 'technological imaginary' of DAB and its distinctly 'European' vision for new media and the future of broadcasting. It examines its origins in European R\&D policy of the 1980s, and its affinity with European broadcasting practice, particularly within a public service tradition. Ironically, it was DAB's failure to capitalise on its 'Europeanness' that contributed to the fragmentary support it subsequently received at a political level, compromising its subsequent implementation. From a contemporary perspective, DAB's original mission to provide enhanced, interactive information and entertainment services through audio, text and visual content, while visionary, appears to have misread trends towards convergence and appears out of step with contemporary consumption patterns.

Keywords: radio, digital audio broadcasting, communication policies. 


\section{Introduction}

Digital radio broadcasting as a concept and as a technology has been in development for over 25 years. Despite many years of investment in research and technology development and the high priority given to digital broadcasting by both broadcasters and government regulators across the world, there is less consensus now about the future of radio than at an $+y$ time in the past. What once may have appeared to have been a fairly straightforward proposition of updating the transmission system, much like the transition from AM to FM at an earlier stage in radio history, now seems much more complicated. Digital radio now represents a complex and thorny problem, complete with competing options and platforms, fragmentation in the market place and disagreement among radio broadcasters and regulators. Recently, digital radio has been disparagingly characterised as the 'Betamax' of radio (Plunkett, 2008) or likened to other failed technology implementations such as AM stereo, introduced in response to new competitive threats (Leblibici et al., 1991).

This paper retraces some of the steps involved in the development of digital radio. Moving back from the current environment where digital radio is hotly debated, particularly among radio professionals who are concerned about the direction the medium is taking in response to competition from satellite and internet radio, this paper examines the origins of digital radio as a proposition when its future seemed to be more certain. Through an analysis of some of the early technical discussion in which the concept of digital radio broadcasting was expounded, I examine some of the original objectives that this new approach to broadcasting was designed to achieve. In particular, I look at a sample of the technical descriptions and promotion undertaken for the European solution, the so-called Eureka-147 or DAB (Digital Audio Broadcasting) system. Eureka-147 is not the only approach to digital radio and, indeed, there is now a proliferation of different systems, posing different challenges to implementation within existing market structures (see Ala-Fossi et al., 2008 for a survey). For instance, while Eureka-147 was initially positively received in the United States, it was ultimately rejected in favour of an alternative approach, the IBOC/HD-Radio system developed by iBiquity. The two systems, the European Eureka-147 standard, and the US IBOC or HD Radio alternative, provide very 
different responses to the evolution of radio into the digital era though both derive from a model of broadcasting that is now under considerable pressure and undergoing substantial change itself.

\section{Why digital radio?}

The digital sublime, as Vincent Mosco has observed, expresses a mythical and utopian vision for how technology can transform society and enable citizens to transcend time, space and politics (Mosco, 2005). The digitalisation of radio, or the conversion of sound processing and transmission to binary digits (World Broadcasting Unions, 1998: 7), is represented, particularly in technical literature, as one example of this all-encompassing, inevitable and necessary vision of how media need to develop in the future. Looked at retrospectively, the predictions made lose their sense of inevitability and appear more arbitrary and contingent but, crucially, enable us to examine with greater clarity the complex of economic, social and political factors involved in shaping technological successes and failures.

In its original context, the extension of digitalization to radio was claimed to complete a process that had been well established in other parts of the media content production chain and which included digital audio production, processing and recording techniques. The prevalence of digital technology in professional radio production environments, replacing older analogue production techniques, as well as the wide penetration of digital consumer formats such as mp3 and the CD format, had by the mid 1980s made the concept of digital audio and its associated benefits widely known in both everyday and professional contexts for radio and audio media.

At the mid point of the 1980s, given the momentum for digitalisation in areas such as telecommunications (ISDN) and storage media for audio (CD), it was widely argued in industry circles that radio sound broadcasting had a pressing need for improvement (Gandy, 2003: 3). Satellite systems for digital transmission, including Digital Satellite Radio and Astra Digital Radio, had already been developed but, significantly, were unsuited to mobile reception where, it was claimed, analogue radio transmission suffered most (Hoeg and Lauterbach, 2001). 
The digitalisation of broadcast transmission systems had been an important and ongoing theme of engineering research for an extensive period of time. In the area of sound transmission, developments such as NICAM stereo sound for television in the early 1970s, and digital transmission technologies for satellite radio (Digital Satellite Radio and Astra Digital Radio) in the early 1980s generated significant momentum in the search for replacement technologies for conventional AM and FM broadcasting (Hoeg and Lauterbach, 2003). The greater efficiency of transmission, resulting in lower costs for broadcasters and transmission networks, as well as greater frequency efficiency, allowing better utilisation of spectrum and the ability to provide more services, made the goal of digital broadcasting an important and attractive one for regulators and governments.

There was and continues to be a strong commercial imperative for radio to become a digital medium and to become part of the trend towards full digital convergence in the media market. Radio, as noted in a recent European Commission study of the digital content industry, is often forgotten about when thinking of convergence and interactive media (Screen Digest, , 2006). Online music distribution, by contrast, has developed into a major new industry expected to be worth $€ 1$.1bn by 2010 and three times that in the United States (Screen Digest, 2006: 12). The same study estimated that there are currently 15 million listeners to online radio in Europe, expected to reach 32 million listeners or 7 per cent of Europeans by 2010, and a further 11 million listeners for podcasting also by 2010 (2006: 13). Against this, the total revenue anticipated by 2010 for all digital radio will be just 5 per cent of the overall advertising revenues for the radio sector and as a result there is major pressure on the industry to find ways to ensure it builds a higher profile in digital content distribution.

As it stands, radio is poised on the cusp of a rapidly expanding environment for digital media services where it can potentially contribute to diverse platforms including handheld mobile devices, online streaming and download services, and multimediarich cable and satellite services. This represents a considerable metamorphosis of radio as traditionally conceived in the one-to-many broadcasting model to stand-alone receivers. It is also, as analysed in the following discussion of its historical context, quite different to the original conception of broadcast digital radio as developed in the Eureka-147 standard. 


\section{Brief Historical Overview of Eureka-147}

Digital Audio Broadcasting or DAB, also known as Eureka-147, has its origins in the European high technology research environment dominated by large equipment manufacturers, broadcasting and telecommunications organizations, and various public and private research institutes. Its development was part of a general effort in the 1980s to develop more efficient transmission systems arising out of the ability to carry information in the form of digital signals. To date, the history of its development has not been extensively documented, though brief historical surveys are available (See for example: Gandy, 2003, Hoeg and Lauterbach, 2003, Kozamernik, 1995b, Lembke, 2003, Kozamernik, 2004, Rudin, 2006).

The DAB project began as a collaboration between Institut für Rundfunktechnik (IRT), the research and development institute for the German broadcasters ARD, ZDF, ORF, and SRG/SSR, and the Centre Commun détudes de Télédiffusion et Télécommunication, the research institute of France Telecom and TDF. Two essential ingredients of the system were already in development prior to the formal organisation of the Eureka consortium: the audio compression or bit-rate reduction system, pioneered by IRT in Germany, and a new radio frequency modulation system called COFDM, led by CCETT in France. The initial basis of the research was the development of an integrated services digital broadcasting system, not specifically dedicated to radio. The DAB bit-stream could in fact be used to transmit all kinds of data including images and slow scan television (Gandy, 2003:3). However, with the crucial support of the European Broadcasting Union (EBU) and leading broadcasting organisations across Europe, including the BBC, a formal consortium of 19 organisations from France, Germany, The Netherlands and the United Kingdom was formed in 1986 to develop DAB as a successor for AM and FM radio broadcasting.

The Eureka Project 147 was established in 1987, with funding from the European Commission, to develop a system for the broadcasting of audio and data to fixed, portable or mobile receivers (ETSI 2006). Phase I of the project consisted of the development of the formal specification of the digital broadcasting system with a second phase up to 1994 to investigate and finalise all aspects of the system to facilitate its adoption as a worldwide standard by international bodies like the European Technical Standard Institute (ETSI) and the International 
Telecommunications Union (ITU). The official project summary describes the research as 'development of a European technical standard for Digital Audio Broadcasting' comprising 'final system standardisation and design, system verification and investigation of implementation aspects'. The technical development envisaged a digitalisation of broadcasting distribution, which would produce improved reception compared to FM, particularly mobile reception, and with the potential to offer additional services such as text and other data, conditional access, enhanced traffic services, and picture transmission (Eureka-147, n.d.: 4).

The DAB system was designed for terrestrial and satellite as well as for hybrid and mixed delivery. Following its adoption by ETSI in 1995 as the single European standard (ETS 300 401) and its recognition by ITU as a terrestrial and satellite broadcasting system, DAB was widely promoted, and demonstrated with regular services being launched in many European countries (Lambert, 1992). In 1995, the European DAB Forum (EuroDAB) was established to co-ordinate and promote the introduction of DAB services. It became the World DAB Forum (World DAB) in 1997 and launched a marketing campaign aimed at supporting a consumer launch from 1997 on (Witherow, 1996). Following completion of the project in 2000, membership of the Eureka 147 consortium merged with World DAB. More recent developments have included the development of the related digital multimedia broadcasting system or $\mathrm{DMB}$, and the adoption of an improved audio codec in a revised DAB + specification. The current body, now known as the WorldDMB Forum is exclusively dedicated to the commercial development and adoption of the DAB family of systems.

\section{Digital radio as symptomatic technology}

The basis of the argument that follows is that the architecture of Eureka-147 DAB offers an encoded understanding or 'technological imaginary' of how radio functions in the world. The concept of the 'technological imaginary' suggests a collective conceptualisation of the potential and promise that a new technology such as digital radio offers (Lister et al., 2003). It provides a discursive basis for the study of technology, particularly from an historical point of view, through which the ideas and visions being promoted express 'dissatisfactions with social reality and desires for a better society..projected onto technologies as capable of delivering a potential realm 
of completeness' (Lister et al., 2003: 60). As such, the technological imaginary of European digital radio expresses a utopian vision for radio broadcasting within the European political and cultural landscape of the time.

In Television: Technology and Cultural Form, his celebrated account of the social history of the origins of television, Raymond Williams (1974) acknowledged the deeply established technological determinism implicit in ways of thinking about communications media and which now largely defines the orthodox view of technology and social change. Less determinist in nature was his category of 'symptomatic technology', a concept which considered 'particular technologies, or a complex of technologies, as symptoms of change of some other kind' (Williams, 1974: 13). In Williams' view, neither pure technological determinism nor a more nuanced notion of symptomatic technology were adequate accounts and made the process of development of technology appear self-generating:

The new technologies are invented as it were in an independent sphere, and then create new societies or new human conditions. The view of symptomatic technology, similarly, assumes that research and development are selfgenerating, but in a more marginal way. What is discovered in the margin is then taken up and used.... These positions are so deeply established, in modern social thought, that it is very difficult to think beyond them. (Williams, 1974)

Compared to pure technological determinism, 'symptomatic technology' is determining in a more 'marginal way' and linked causally to the social context in more complex fashion. Williams does not develop the concept further in Television: Technology and Cultural Form and ultimately rejects it in favour of a social theory of technology which removes the dichotomy between technology and society.

However, I think there is some merit in thinking about digital radio as a symptomatic technology, and that among its determining features are such important considerations as the conceptions and ideas brought forward within the relatively specialised environments of broadcast engineering, their respective institutional ideologies, as well as the overarching priorities determined by funding agencies and sponsoring institutions. This is an approach that fits well with the tradition of research centred around social shaping of technologies or SST (MacKenzie and Wajcman, 1985), now 
an important research agenda in the study of technological innovation (Williams and Edge, 1996). While signifying a constructivist approach to the development of new technologies, it is, as Williams and Edge argue, a 'broad church' of sociological studies of social and economic contexts in which technologies emerge, develop and are ultimately 'shaped' to social ends.

Mackay and Gillespie (1992) characterize Williams' account of the development of television as a pioneering example of an SST approach. They argue, though, that as it stands, SST studies have paid insufficient attention to the role of ideology either at a micro or a macro level of the development of technology. Ideology, they observe, is conspicuously absent in Williams' account of the social shaping of television (1992: 692). While due attention to technology as social construct has been centrally important in extending our understanding of why technology is as it is, fear of determinism has led to insufficient attention being given to the ideologies underpinning technology development and to the crucial developmental input of engineers and designers. It is such ideological constructions, I suggest, that make technology symptomatic, an articulation of the distinct conditions linked in discourse of what a technology purports to do. Relatedly, Flichy, in his study social shaping of ICTs, has called attention to the many potentially different histories of technologies, comprising the distinct perspectives of 'designers, $R \& D$ engineers, marketing specialists, salespeople, repairers, partner companies (manufacturers of components, content providers, etc.)' (Flichy, 2002: 136). Within such relationships, engineers' representations represent crucially important choices that are subsequently significant for the trajectory of the development of the technology.

This points to the second dimension in which Mackay and Gillespie (1992) suggest an SST approach needs to be extended, namely, by acknowledging the role of marketing or promotion in the shaping of the technology. The set of needs that a technology is designed to address is not created, they argue 'in the autonomous sphere of individual motivation...but heavily dependent on the productive system' (1992: 695). Central to the R\&D process is the essential function of communication and dissemination of research results, and promotion of the benefits of scientific findings. Over its extended history of development, digital radio has been widely discussed, disseminated, and promoted in a variety of settings including scientific and technical conferences, 
industry exhibitions, technical press and trade publications as well as policy and strategy documents. Within this arena, the promise and potential of digital radio has received its fullest expression as engineers, lobbyists and publicists have sought to make the case for greater governmental and commercial support. Such appeals provide the basis for much of the foregoing analysis. Close attention to such technical and promotional discourses provides access to an important articulation of the rationale underpinning the technology, what it was designed for and the problems it was intended to solve. This is not to privilege a 'technicist' version of digital radio but rather to complement, through symptomatic analysis, how digital radio is intended to meet needs identified and articulated through the scientific and technical broadcasting community.

In the case of digital radio, a crucial element of the effort involved in securing acceptance of the new standard was wide dissemination, promotion and marketing of the system's attributes and benefits for both radio professionals and for listeners. The combined efforts of organisations such as EuroDAB, later WorldDAB, the European Broadcasting Union as well as individual broadcasters sought to bring awareness of the new system to as wide an audience as possible and to promote a consistent and well rehearsed message of the advantages that DAB offered. This body of combined technical and promotional appeals regarding the features, benefits and potential for the new technology conveyed an overall vision of what, in the minds of its developers, the medium was capable of and how it might further develop in the future.

\section{The attributes and benefits of Eureka-147}

The digital radio system developed under Eureka-147 is widely acknowledged to be a highly successful technical feat of engineering that provides an innovative approach to digital audio and multimedia broadcasting (Hoeg and Lauterbach, 2003). It has been claimed to be the most significant development since the introduction of FM stereo broadcasting (Bower, 1998). It incorporates a range of advantages over conventional broadcast systems and was intended, at least originally, to be a replacement technology for AM and FM radio broadcasting (Hoeg and Lauterbach, 2003).

The definitive technical manual of Digital Audio Broadcasting (Hoeg and Lauterbach, 2003) defines the following benefits of the Eureka-147 system: 
1. Quality of Service - the utilization of digital technology to provide listeners with a higher quality of service including superior sound quality, better usability and perfect reception.

2. Value-Added Services - the capability of one multi-functional receiver to include broadcasting services, accompanying programme associated data, additional information services, and still or moving pictures.

3. A Universal System Layout - allowing for the wide availability of the service on fixed, mobile and portable receivers and across terrestrial, satellite, and cable networks.

4. Flexible multiplex configuration - a transmission method which enables broadcasters to arrange multiple services in a DAB 'multiplex' and to vary the quantity and quality of services through bit rate adjustment.

5. Transmission efficiency - offering lower transmission costs for broadcasters and network providers as well as efficient spectrum use through the arrangement of Single Frequency Networks (SFNs)

Two distinct categories within the above stand out: firstly, there are those technical and operational advantages of the standard that are relevant to the professional radio industry; and secondly, there are those features which promise an improved quality of service and user functionality, and which are intended to provide audiences with an enhanced listening experience. The benefits of the Eureka standard, as identified above, were widely disseminated among a variety of publics and provided the basis for extensive promotion of the system in each of the markets in which it was introduced. This promotional exercise included a wide range of technical presentations and demonstrations which sought to convey the essential vision of the new system and to persuade the different stakeholders of DAB's merits.

The overriding advantage of Eureka-147, which was intended to appeal to both consumers and to the technical broadcasting community, was its proposed enhanced quality of transmission and interference-free reception. The BBC claimed that the consistency of high quality transmission even in adverse conditions was the single most important reason for considering DAB as the future of radio (Gandy, 2003: 2). The age old problem of multi-path interference, or disruption to the radio signal caused by reflections and shadowing by high buildings particularly in dense urban 
areas, had been identified as one of the main problems associated with analogue broadcasting. For the listener, this resulted in poor quality reception, fading signals and noise interference (Maddocks, 1994). This was especially the case for in-car reception and on portable receivers and was considered a real constraint to the further growth of radio as a medium (World Broadcasting Unions, 1998). Stereo FM, when it was introduced in the 1950s, was, strictly speaking, designed for reception via a fixed, static receiver with a roof-top, directional antenna (Lau and Williams, 1992, Shelswell. et al., 1991). Clearly, improvements in receiver design had created acceptable listening conditions for FM, which included switching to mono when reception deteriorated. From an engineering point of view, however, FM was never designed for mobile and in-car reception. A key design parameter for $\mathrm{DAB}$ was, therefore, quality of reception in fastmoving vehicles, even in extreme conditions. DAB's innovative solution to the problems of reception was to use multiple signal reflections in a constructive way within a new modulation system called COFDM (coded orthogonal frequency division multiplex) which had the effect of successfully combating multi-path interference (Bower, 1998).

A related feature of the COFDM approach was the ability to use a single frequency block with multiple transmitters over an extensive area without mutual interference, allowing broadcasters to plan services in what is known as a Single Frequency Network (SFN) (Lau and Williams, 1992: 12). Echoing its origins in satellite systems research, DAB's Single Frequency Network approach is such that it is typically optimized for large national or regional areas in situations which offered the greatest spectrum efficiency. The more localized the service required, the more frequencies are needed and the system becomes less spectrally efficient. Equally, the optimal solution to ensure the most costefficient coverage was discovered to be a network of closely-spaced, relatively low powers transmitters. As such, planning for digital transmission was conceived on the basis that nationally-based or regionally strong networks (such as the BBC) would be primarily responsible for managing the network rather than individual local stations organizing their own transmission.

A further feature of the DAB transmission system that was unfamiliar to broadcasters at the time was its organization into a service multiplex or ensemble of programme services, of typically up to six stereo channels (Riley, 1994). The flexibility to dynamically vary the composition of the service according to need, such as splitting a stereo programme into two separate mono channels, or to provide an additional language channel as required 
offers the multiplex operator considerable control over service planning. From the listener's perspective, access to services is facilitated through a menu function, based on adaptation of the RDS or Radio Data System in which text labels identify station tuning and programme content. The multiplex organization is all but invisible to the listener who simply has to choose by station or service identification. From the broadcaster point of view, the organization of programming services into a complex arrangement involving different service provides represents a significant reorganisation of the transmission chain. From the relatively simple structure of broadcaster acting as programme provider and feeding final content into the broadcast chain for transmission and distribution, DAB introduces the distinct functions of programme provider, data service providers and multiplex or ensemble provider (Hoeg and Lauterbach, 2003: 152). Organisationally, the $\mathrm{DAB}$ configuration requires effective co-ordination between each of the elements of the service and as such is again optimally suited to the large broadcaster, multi-service broadcaster with the relevant technical and programming resources to utilise all aspects of the DAB service. An idealised DAB service provision model, as such, maps closely to the kind of programme services envisaged by public broadcasting organisations such as BBC, Danmark Radio or Bayerische Rundfunk who provide suites of diverse programme material, associated programme data and other listener services under a common brand.

\section{DAB's enhanced user features}

Alongside its radical reconceptualisation of the broadcasting chain of production, the Eureka system also proposes a different of mode of listener engagement with radio, with some significant changes in the way audiences would experience its service. For instance, $\mathrm{DAB}$ researchers from an early stage considered the user interface of receiver design and proposed a number of different ways in which typical listener needs might be built into the technology. The multiplexed nature of the DAB service, combining different types of information as potentially numerous programme channels, presented challenges for a suitable interface design. In addition to the main audio service, for instance, DAB can potentially offer a host of additional information including text and images, detailing the name of the service, e.g. 'BBC RI Digital'; a programme type label, e.g. 'News', 'Sport', 'Classical Music'; time and date, for display or recorder control; as well as traffic reports, news flashes or announcements on other services (Tuttlebee and Hawkins, 1998: 266). The design principle was that DAB radios 'should be characterized by abstraction from technical details and that service access should be 
content based, so that a listener can "forget" the technical delivery mechanism' (Marks, 1998: 5). The HuMIDAB project in 1998, comprising WorldDAB, Clarion, Sony and Bosch, BBC, Radio France and Swedish Radio as partners, proposed a variety of interfaces, in particular for in-car systems, utilising touch screen interfaces and EPG menu systems as ways of accessing DAB audio and data information services (Riley, 1994).

Early market research suggested positive interest among the general public for the features offered by DAB. Three broad market segments or applications for new DAB services were targeted by broadcasters as particularly important (Tuttlebee and Hawkins, 1998: 268).

First, in-car listening, as mentioned above, was identified as a top priority for the $\mathrm{DAB}$ project. Eureka-147 was the first transmission system designed specifically with the motor vehicle in mind and had perfected a system to deliver near-CD quality with no signal loss or fading as a car traversed the country, even at high speed. The major defects of analogue radio, it was claimed, were most apparent in moving vehicles both in urban conditions and on cross national routes. Medium-wave reception, for instance, was best problems of low audio quality, often marred by interference from electrical equipment or distant stations. FM reception fluctuated considerably as vehicles went past buildings, over hills and down into valleys, and radio receivers had to be retuned as the car moved out of range of one transmitter and into range of another (Fox, 1994b). DAB as a result offered a quality of service never previously attained through its robust reception and linkage to a single frequency network.

The attraction of an all-digital audio entertainment system as well as the potential of high speed datacasting to vehicles, incorporating GPS navigation systems, traffic management information and high quality images, were conceived as potentially DAB's 'killer application'(Yamauchi et al., 1995: 74, Shelswell. et al., 1991, Müller-Römer, 1997). The mobility of high quality digital radio was also such as to rearrange the frontiers of broadcasting in a way that analogue broadcasting had severely constrained. An early description conveyed the promise of DAB as 'radio sans frontieres':

Imagine driving the length of Britain, over the Channel and across Europe, listening all the time to the same radio station. The sound is in digital stereo, which gives it the same quality as that from a compact disc. There is no 
interference, and none of the fading and fluttering that normally blemish reception as you drive past tall buildings, over hills and down valleys. There is no need to keep retuning the radio because the chosen station remains on the same frequency throughout Europe - although, of course, you could retune to alternative national, international or local stations if you wanted to. (Fox, 1991)

A second market segment envisaged as important for early adoption of the DAB radio standard was of hi-fi audio enthusiasts. As a group of early adopters, audiophiles were considered to be an important means of broadening the consumer market for $\mathrm{DAB}$ for both fixed and portable receivers. An assumption of the period was that the advent of digital audio formats such as the $\mathrm{CD}$ had created a demand for uniform, high quality audio in radio (Maddocks, 1994). A number of high end audio receivers were developed by companies such as Arcam building on the wide acceptance of $\mathrm{CD}$ as the benchmark audio standard (Josse, 2002). This emphasis on DAB's audiophile credentials was and continues to be an important component of the marketing strategy for digital radio, despite ongoing controversy regarding its implementation (Spikofski and Klar, 2003), and claims for a radio listening experience of unsurpassed quality were central appeals of the new radio format. Again, a scenario envisioning the compelling features of the DAB listening experience is presented in this extract from an IEEE publication dating from 1996:

Returning home from a business trip, Doug Digital turns on his car radio and enters code 15 for classical music. After the radio selects an appropriate strong-signal digital audio broadcasting station, Doug hums along, adding his voice to the compact-disk quality sound of the selection, which is free of any interference or signal fading despite the hilly terrain. He likes the music, but cannot put his finger on what it is, so he glances down at the radio's liquidcrystal display and reads the name of the selection and the performing artists. As he travels farther away from the station's transmitting facility, the radio switches to a stronger station airing the same classical programming, without his noticing the changeover.

...When Doug gets home, he and his wife have dinner and then decide to listen to a live concert of the New York Philharmonic orchestra. Doug requests 
the concert from the pay-per-listen digital audio radio service he subscribes to and the two settle back, listening to it in five-channel Dolby Surround on their stereo system. After the concert, Doug decides to add features to his digital audio radio system, including programming it with a "pick list" for advertising offers so that be will automatically be informed of products that interest him. (Jurgen, 1996: 52)

Finally, one further segment identified as an important potential new market for the features offered in DAB was that of personal computer users. PC-card DAB receiver applications targeted at internet users could better exploit the dynamic programme text capabilities of $\mathrm{DAB}$ and had the potential to integrate internet use with high quality audio reception (Tuttlebee and Hawkins, 1998: 268). At a time when internet connectivity was still predominantly based on dial-up connections, DAB receivers as additional modules for PCs could enhance a multimedia experience and offer potential for greater interactivity and e-commerce applications.

Alongside DAB's technical attributes as a new form of radio, an important element of the overall promotional discourse was its claims to be the definitive future of radio, underpinned by the certainty that all media would in the future be digital. The dominant trope of mid 1990s technical discourse of audiovisual services was the conviction that all traditional media including radio, television and the press would adopt digitally-based delivery systems and that varying elements of convergence between different media would emerge (Kozamernik, 1995b: 3). Through various events and demonstrations, DAB was presented and believed to herald a new revolutionary era in radio broadcasting (Nunn, 1995, Witherow and Laven, 1995). Allied to this was a further belief in the necessity for radio to rapidly embrace digital technology to survive in an increasingly competitive and complex market. DAB, it was claimed, provided the opportunity to keep 'radio not only alive but healthy in an increasingly competitive environment' (Witherow and Laven, 1995: 61). Conversely, radio could be marginalised in a multimedia environment if it remained analogue (Kozamernik, 1999). 


\section{European technology: global vision}

Rather than any one distinct contribution, DAB development as described above involved a series of discrete, co-ordinated engineering innovations designed to solve specified research problems in the area of digital signals transmission. It is a product of the European R\&D high technology infrastructure, emanating from research labs specialising in telecommunications and radio communications research, sponsored by large broadcasting corporations and funded through the inter-governmental Eureka investment programme. But to what extent might one describe DAB as a European technology, one that was distinctively shaped by the environment in which it was developed, and to what extent did it proceed to carry meanings and purpose that were expressions of the visions of its creators?

One of the ways in which DAB's credentials as a 'European' technology of significant proportions have been endorsed has been through its close association with the European Broadcasting Union or EBU. As the representative European organisation for national public broadcasting organisations, the EBU has from the very start been central to the development of digital radio broadcasting. The EBU had initiated the first series of studies on satellite DAB in the mid 1980s and supported the formation of the consortium for Eureka-147. EBU members were the driving force behind the consortium and the EBU's Technical Department actively participated in its various working groups. Crucially, the EBU as an international organisation provided essential logistical support in promoting DAB in the ITU and in the preparation prior to the adoption of DAB as an ETSI standard (Kozamernik, 1995a: 10). Public radio broadcasters were and continue to be in the forefront of European digital radio services and are the driving force for digitization 'from technical testing, to content provision, to marketing and promoting the platform' (EBU-UER, 2007: 8). More importantly, the EBU has argued, public broadcasters have been to the fore in promoting the benefits of digitization to citizens and act as the social force underpinning the provision of services on a basis that commercial broadcasters would be unable and unwilling to do. As such, digital radio in the European context has always been closely associated with and allied to the institutional visions and infrastructure of European public broadcasting in both form and content, and as 
argued above, articulated through the actual architecture of a system suited to its needs rather than to other forms of broadcasting.

A further element of this 'symptomatic' explanatory framework relates to the industrial development policy objectives underpinning the Eureka support for digital radio technology. Lembke's (2003) comprehensive account of the high technology development environment of the European Union has described its policy and technology investment framework as one which was focused on supporting European technology leadership at a global level, particularly in the field of consumer electronics. A key objective of European investment in technologies like digital radio, mobile communications and in satellite navigation systems, he argues, was to enable standardisation at, firstly, a European and, subsequently, a global level in order to create opportunities for world leadership in high technology systems, thereby providing a counterbalance to the dominance of the electronics sector in the Far East (Lembke, 2003: 212). With regard to digital radio, it was assumed that with the establishment of a common European standard, significant opportunities would be available for the European entertainment electronics industry to develop a whole range of new products for the domestic and automobile sectors. The development of DAB was characterised as an attempt to emulate the success of GSM, the global standard for mobile phone communication, developed with strong European backing:

After the digitisation of communications, digital radio is probably, after digital $\mathrm{TV}$, the last chance for Europe to enhance its competitiveness in the consumer electronics sector. [...] Europeans who developed the system and invested most in $\mathrm{DAB}$, have to put all their efforts to participate in the exploitation of the system. With such a joint European efforts DAB can and will repeat the success story of GSM.. (in Lembke, 2003: 214)

Initial expectations were high for $\mathrm{DAB}$ as a consumer electronics item and market research suggested that Europeans could buy 50 million DAB sets in the first 10 years, with sales then rising to 35 million a year. This compared very favourably with the seemingly ubiquitous CD player, which took eight years to achieve annual sales of 5 million (Fox, 1994a). 
Central to this strategic vision of developing a global standard for digital radio broadcasting was the requirement for public intervention at a pan-European level, necessitating a political commitment and institutional backing to include the development of a stable regulatory framework, co-ordination of frequency allocation and a co-ordinated strategic approach to supporting market adoption of the system.

Strengthening the competitiveness of the European audiovisual industry has been a European policy priority since the mid 1990s with an emphasis on the development of a single market, support for regulatory harmonisation and an enhanced, centralised role for the European Commission in the communications sector (Kaitatzi-Whitlock, 1996, Levy, 1999, Harcourt, 2002). While the focus of European policy has concentrated on the cinema and television sectors, for instance through the Television Without Frontiers directive and the MEDIA programme, a central aim of the participating partners in Eureka-147 was to lobby Brussels for an equivalent level of political attention and support for the digital radio sector. From its inception, the ambition of the DAB consortium was to be the defining global standard for the digital system to replace analogue AM and FM broadcasting. Within European policy terms, Eureka-147 was the radio industry's vision of its role within communications convergence and the digital revolution. Its successful early development and adoption as the first digital broadcasting standard, before rival systems such as DVB, suggested that little public intervention would be needed (Liikanen, 2001). Its subsequent sluggish pace of adoption led to renewed calls for more direct European support. Michael McEwen, then chairperson of WorldDAB, argued to the European Commission in 1998 that the rest of the world was looking to Europe for a lead in the roll-out of DAB: 'If it is not led by Europe,' it was argued, 'then how can you expect the rest of the world to adopt a European technology?'(European Commission, 1998)

However, the European policy commitment to removing regulatory barriers, market intervention and the principle of 'technological neutrality' in liberalised communications markets, meant in European Commission terms that, success or failure was primarily the responsibility of market players (Liikanen, 2001: 4). The radio industry attempted to argue that there was a 'European' dimension to digital radio, i.e., an element of public policy that could only be satisfactorily addressed at a European rather than at a national level, and that diverging regulatory frameworks and 
implementation strategies in the Member States would lead to fragmentation of the European market. Manufacturers, for example, strenuously argued that the fragmented and disjointed roll-out of digital radio, with successful implementation in some countries and very little in other, was a serious impediment to the development of a new market for digital radio receivers. The prevailing understanding that radio was a local medium, and the primary responsibility of diverse national and regional authorities, however, worked against any further European co-ordinated action and as a consequence decisive European Commission support was always qualified.

\section{Conclusion}

The guiding assumptions underpinning the development of Eureka-147 DAB were that a robust and mature technology developed within Europe's highly regarded high technology research environment would provide an ideal replacement standard for the international radio broadcasting industry. DAB's version of digital radio built on the proud experience of its trusted and oldest broadcasting institutions, and looked confidently to an imagined future in which the major broadcasting institutions would continue to provide more content of higher quality and in interactive and multimedia formats. It represented an exemplary model of co-operation between European member states and between public broadcasting organisation and private manufactures with the guiding and financial support of agencies such as Eureka and the EBU. Its early success in technology design and rapid development of a fully working system suggested that it would be a great success as GSM had been previously, and would contribute further to Europe's leading role in global technology development. DAB did achieve rapid early success in attaining international standardization, with adoption of the basic DAB standard by ETSI in 1993, followed by the ITU-R recommendation of DAB as the only digital radio standard in 1994. The allocation of spectrum for terrestrial digital radio broadcasting by the World Administrative Radio Conference (WARC) in 1992 provided a major boost to its international standing and launched its efforts towards implementation in Western Europe and beyond.

Despite these early, promising indicators, DAB deployment stalled and continues to languish in an extended period of early market deployment and adoption with both 
ongoing successes and reversals. Lacking the sense of urgency and political priority given to analogue switch off for television, radio now contends with a multiplicity of delivery mechanisms, analogue and digital, and has deferred the question of whether AM and FM broadcasting needs to be replaced. Strategies for the introduction of digital radio are characterised by a liberal market approach where it is largely been left to market forces to decide the fate of particular technologies. As with previous technological developments in the sector, this resulted in long delays in new technology development, competing solutions, confusion for the radio industry and for audiences; and an uncertain environment for future planning. Ironically, it was the failure of the radio industry as a whole to convince the European Commission of the 'Europeanness' of Eureka-147, or that there was a 'European' question that merited intervention, that led to a situation where it received only fragmentary support. The appeals by the sector that strong market intervention was needed to created an extended single market, with harmonised approaches to spectrum planning, and market regulation, coincided with a shift in policy towards a market for content as opposed to support for particular media such as radio or television. As a consequence, responsibility for realising the potential of digital radio remained at a local and national level, and inextricably bound up with the cultural and political struggles for support and control of broadcasting in individual member states. 


\section{References}

ALA-FOSSI, M., JAUERT, P., LAX, S., O'NEILL, B. \& SHAW, H. (2008) The Future of Radio is Still Digital - But Which One? Expert Perspectives and Future Scenarios for Radio Media in 2015 Journal of Radio \& Audio Media, 15.

BOWER, A. J. (1998) DIGITAL RADIO - The Eureka 147 DAB System. Electronic Engineering.

EBU-UER (2007) Public Radio in Europe 2007. Geneva, European Broadcasting Union.

EUREKA-147 (n.d.) EUREKA PROJECT 147- DAB (IMP).

EUROPEAN COMMISSION (1998) Radio in the digital era: A Report on the Meeting organised by the European Commission (DG X). European Commission ( $D G X)$. Brussels.

EUROPEAN TELECOMMUNICATIONS STANDARDS INSTITUTE (2006) Radio Broadcasting Systems; Digital Audio Broadcasting (DAB) to mobile, portable and fixed receivers. Sophia Antipolis Cedex - FRANCE.

FLICHY, P. (2002) New Media History. IN LIEVROUW, L. \& LIVINGSTONE, S. (Eds.) The Handbook of New Media, Social Shaping and Consequences of ICTs. London, Sage.

FOX, B. (1991) Radio sans frontieres: By the mid 1990s, people driving across Europe should be able to tune into their favourite radio programmes in hi-fi wherever they are. New Scientist.

FOX, B. (1994a) Britain clears the airways for digital radio. New Scientist. London, Reed Elsevier, Inc.

FOX, B. (1994b) The perfect sound machine. The Times. London, Times Newspapers Limited

GANDY, C. (2003) DAB: an introduction to the Eureka DAB system and a guide to how it works. $B B C R \& D$ White Paper.

HARCOURT, A. (2002) Engineering Europeanization: the role of the European institutions in shaping national media regulation. Journal of European Public Policy, 9, 736 - 755.

HOEG, W. \& LAUTERBACH, T. (2001) Digital Audio Broadcasting: Principles and Applications, John Wiley \& Sons Ltd, Chichester, United Kingdom.

HOEG, W. \& LAUTERBACH, T. (2003) Digital Audio Broadcasting Principles and Applications of Digital Radio, Chichester, John Wiley \& Sons.

JOSSE, D. (2002) DAB - now hitting the market on an industrial scale. $E B U$ Technical Review, October 2002.

JURGEN, R. K. (1996) Broadcasting with digital audio. IEEE Spectrum, 33, 52-59.

KAITATZI-WHITLOCK, S. (1996) Pluralism and Media Concentration in Europe: Media Policy as Industrial Policy. European Journal of Communication, 11, 453-483.

KOZAMERNIK, F. (1995a) Digital Audio Broadcasting — radio now and for the future. EBU Technical Review, Autumn 1995.

KOZAMERNIK, F. (1995b) Eureka 147 to a worldwide standard. IN NUNN, J. (Ed.) $D A B$ - The Future of Radio London, Audio Engineering Society

KOZAMERNIK, F. (1999) Digital Audio Broadcasting - coming out of the tunnel. EBU Technical Review, No. 279. 
KOZAMERNIK, F. (2004) DAB - From digital radio towards mobile multimedia. EBU Technical Review, No. 297.

LAMBERT, P. (1992) DAB: Signs of coming down to Earth. Broadcasting, 122, 37$1 / 2$.

LAU, A. \& WILLIAMS, W. F. (1992) Service planning for terrestrial Digital Audio Broadcasting. EBU Technical Review, Summer 1992.

LEBLIBICI, H., SALANCIK, G., COPAY, A. \& KING, T. (1991) Institutional Change and the Transformation of Interorganizational Fields Administrative Science Quarterly 36, 333-363.

LEMBKE, J. (2003) Competition for Technological Leadership: EU Policy for High Technology, Cheltenham, Edward Elgar Publishing.

LEVY, D. A. (1999) Europe's digital revolution broadcasting regulation, the EU, and the nation state, New York, Routledge.

LIIKANEN, E. (2001) Prospects for Digital Radio Development in the European Union. World DAB Annual General Assembly. Brussels.

LISTER, M., KELLY, K., DOVEY, J. \& GIDDINGS, S. (2003) New Media: A Critical Introduction, London Routledge.

MACKAY, H. \& GILLESPIE, G. (1992) Extending the Social Shaping of Technology Approach: Ideology and Appropriation. Social Studies of Science, 22, 685-716.

MACKENZIE, D. A. \& WAJCMAN, J. (1985) The Social shaping of technology how the refrigerator got its hum, Milton Keynes; Philadelphia, Open University Press.

MADDOCKS, M. C. D. (1994) Digital audio broadcasting (DAB)-radio for tomorrow. IEE Colloquium on Audio Engineering. London, UK, IEEE.

MARKS, B. (1998) The HuMIDAB project - looking at the Human Machine Interface of digital radios. EBU Technical Review, 278.

MOSCO, V. (2005) The Digital Sublime: Myth, Power, and Cyberspace, Boston, MA., The MIT Press.

MÜLLER-RÖMER, F. (1997) DAB progress report - 1997. EBU Technical Review, Winter 1997.

NUNN, J. (1995) Introduction. IN NUNN, J. (Ed.) DAB - The Future of Radio London, Audio Engineering Society

PLUNKETT, J. (2008) Is DAB radio the next Betamax? The Guardian.

RILEY, J. (1994) DAB multiplex and system support features. EBU Technical Review, Spring 1994.

RUDIN, R. (2006) The Development of DAB Digital Radio in the UK: The Battle for Control of a New Technology in an Old Medium. Convergence, 12, 163-178.

SCREEN DIGEST LTD, CMS HASCHE SIGLE, GOLDMEDIA GMBH \& LTD, R. (2006) Interactive content and convergence: Implications for the information society. European Commission, Information Society and Media.

SHELSWELL., P., C. GANDY, RILEY, J. L. \& MADDOCKS, M. (1991) Digital Audio Broadcasting. IEE Colloquium on Vehicle Audio Systems. London, UK.

SPIKOFSKI, G. \& KLAR, S. (2003) DAB and CD quality - reality or illusion. $E B U$ Technical Review, October 2003.

TUTTLEBEE, W. H. W. \& HAWKINS, D. A. (1998) Consumer digital radio: from concept to reality. Electronics \& Communication Engineering Journal, 10, 263-276.

WILLIAMS, R. (1974) Television: Technology and Cultural Form, London, Fontana. 
WILLIAMS, R. \& EDGE, D. (1996) The social shaping of technology. Research Policy, 25, 865-899.

WITHEROW, D. (1996) Digital Audio Broadcasting - On the way. EBU Technical Review, Winter 1996.

WITHEROW, D. M. L. \& LAVEN, P. A. (1995) Digital audio broadcasting-the future of radio. International Broadcasting Convention, IBC 1995. Amsterdam, Netherlands, IEEE.

WORLD BROADCASTING UNIONS (1998) Digital Radio Guide.

YAMAUCHI, K., KAKIUCHI, S., TAKEBE, A. \& SUGITOMO, M. (1995) Digital Audio Broadcasting receiver development. International Broadcasting Convention, IBC 1995. Amsterdam, Netherlands, IEEE. 